\title{
A COMPARATIVE STUDY OF MEDIAN AND PARAMEDIAN TECHNIQUES TO IDENTIFY THE LOWER THORACIC EPIDURAL SPACE AND CATHETER INSERTION FOR UPPER ABDOMINAL SURGERIES
}

\author{
Liyakath Raja'1, Pichai Lenin², Pachaimuthu Elango ${ }^{3}$, Gurusamy Sivakumar', Anbu Srinivasan ${ }^{5}$
}

${ }_{1}^{1}$ Senior Assistant Professor, Department of Anaesthesiology, Government Thiruvarur Medical College, Thiruvarur. ${ }^{2}$ Senior Assistant Professor, Department of Anaesthesiology, Government Thiruvarur Medical College, Thiruvarur. 3 Professor, Department of Anaesthesiology, KAP Viswanatham Government Medical College, MGMGH, Tiruchirapalli. 4Professor, Department of Anaesthesiology, KAP Viswanatham Government Medical College, MGMGH, Tiruchirapalli. ${ }_{5}^{5}$ Associate Professor, Department of Orthopaedics, KAP Viswanatham Government Medical College, MGMGH, Tiruchirapalli.

ABSTRACT
BACKGROUND
Epidural is a central neuraxial blockade with various applications. The epidural space was first described by Corning in 1901. And
Fidel Pages first used epidural analgesia in humans in 1921. Fidel Pages described the interspinous approach to the epidural space
and reported satisfactory anaesthesia for abdominal procedures. Improvements in equipment, drugs and technique have made it a
popular and versatile anaesthetic technique, with applications in Surgery, Obstetrics and Pain relief. Both single injection and
catheter techniques can be used. Its versatility means it can be used as an anaesthetic, an adjuvant to general anaesthesia and for
postoperative analgesia in procedures involving the lower limbs, perineum, pelvis, abdomen and thorax. This study compares the
median and paramedian epidural techniques to identify the lower thoracic epidural space and catheter insertion for upper
abdominal surgeries.

\section{METHODS AND MATERIALS}

This is a comparative, randomised, double-blinded prospective study comparing median and paramedian approaches to identify the lower thoracic epidural space and catheter insertion for upper abdominal surgeries in two groups of patients comprising of fifty patients each. The observations were analysed using Epi info software and ANOVA measure for students' test and Chi-square test to compare the data between the two groups.

\section{RESULTS}

This study shows paramedian approach of identification lower thoracic epidural space has less number of attempts, less incidence of dural tap, easy insertion of catheter, less incidence of pain, less time taken to identify the epidural space and less resistance to catheter insertion than the median approach.

\section{CONCLUSION}

The location of epidural space in patients posted for upper abdominal surgeries was found to be easier and has lesser complication by paramedian approach when compared to median epidural approach.

\section{KEYWORDS}

Epidural Analgesia, Epidural Space, Identification, Epidural Catheter.

HOW TO CITE THIS ARTICLE: Raja L, Lenin P, Elango P, et al. A comparative study of median and paramedian techniques to identify the lower thoracic epidural space and catheter insertion for upper abdominal surgeries. J. Evolution Med. Dent. Sci. 2017;6(95): 7003-7008, DOI: $10.14260 /$ jemds/2017/1520

\section{BACKGROUND}

Epidural anaesthesia is a central neuraxial blockade with various applications. The epidural space was first described by Corning in 1901 and Fidel Pages first used epidural anaesthesia in humans in 1921. Fidel Pages described the interspinous approach to the epidural space and reported satisfactory anaesthesia for intra-abdominal procedures.

In the early 1930s, Archile Mario Dogliotti, ${ }^{1}$ building on Jansen's discovery of negative pressure in the epidural space, described a practical technique for administering lumbar segmental anaesthesia. Using Dogliotti's work as a foundation, Gutierrez in 1932, described the hanging drop technique to

'Financial or Other Competing Interest': None.

Submission 02-11-2017, Peer Review 04-12-2017,

Acceptance 11-12-2017, Published 23-12-2017.

Corresponding Author:

Dr. Pichai Lenin,

No.17, Arockiasamy Nagar,

Kumbakonam.

E-mail:drplenin@yahoo.com

DOI: $10.14260 /$ jemds $/ 2017 / 1520$

identify the epidural space.

A year earlier, Eugene Aburel placed a silk urethral catheter in the epidural space and used it to block the pain of women in labour. During World War II in America, Robert Hingson was assigned to care for the pregnant wives of United States Coast Guard seamen. Stationed at a U.S. Public Health Hospital, Hingson wanted to develop a method whereby he could alleviate the pain of labour in these women. Unaware of Aburel's work, Hingson took Lemmon's malleable needle and placed it sacrally, deep to the peridural ligament. This safe and effective method of producing painless childbirth became popularly known as continuous caudal anaesthesia.

In 1949, Manuel Martinez Curbello modified a silk catheter for continuous spinal anaesthesia and inserted it into the epidural space, thus creating the first continuous epidural block. By 1962, the first polyvinyl catheter with a closed tip was introduced, making the continuous epidural block much easier to perform correctly.

In 1945, Tuohy introduced the needle which is still most commonly used for epidural anaesthesia. Improvements in equipment, drugs and technique have made it a popular and 
versatile anaesthetic technique, with applications in Surgery, Obstetrics and Pain relief. Both single injection and catheter techniques can be used..$^{2}$ Its versatility means it can be used as an anaesthetic, an analgesic adjuvant to general anaesthesia and for postoperative analgesia in procedures involving the lower limbs, perineum, pelvis, abdomen and thorax. ${ }^{3}$

\section{MATERIALS AND METHODS}

This study was conducted in Govt. Chengalpattu Medical College, Chengalpattu from 2009-12. This is a comparative, randomised, double-blinded prospective study of median and paramedian epidural techniques to identify the lower thoracic epidural space and catheter insertion for upper abdominal surgeries. Ethical committee clearance was duly obtained from the Hospital.

\section{Inclusion Criteria}

- $\quad$ ASA I \& II.

- Age 20 - 60 years.

\section{Exclusion Criteria}

- Refusal for regional anaesthesia.

- Coagulopathy.

- Unstable haemodynamic status.

- Local Sepsis.

- Intracranial space occupying lesions.

Based on the previous study, ${ }^{4}$ at a power of $80 \%$ the difficulty to identify the epidural space in median approach was $24 \%$ and paramedian approach was $4 \%$ with allocation ratio of 1 . The calculated sample size found to be 47 in each group. This study was conducted on 100 patients undergoing various abdominal surgeries. Block randomisation technique used to allocate the patients to Group M and Group P. Blocks of varying sizes ranging from $2-6$ used for block randomisation. Informed consent was taken from all the patients. Preoperative evaluation was done.

Anaesthesiologist who is blinded to the study was requested to do the epidural block. Study group was divided into Group M and Group P. Each group consists of 50 patients. GROUP M -Median epidural approach (50 patients). GROUP P -Paramedian epidural approach (50 patients).

\section{Patient Positioning}

Careful attention to the patient's position is essential for successful placement of the epidural needle and catheter. ${ }^{5}$ Depending on the patient's medical status, weight and ability to cooperate, the sitting position can ideally be chosen. In general, it is technically easier to identify the paramedian in an obese patient in the sitting posture, but this requires the assistance of a trained person to maintain the correct posture. ${ }^{6}$ Monitoring equipment and oxygen may be attached to the patient before or after the patient is positioned. The operating table should be adjusted according to the anaesthesiologist's comfort. Privacy should be assured to the patient by means of blankets or covering sheets and patient feet should be comfortably resting on stool. In case patient is made to sit, an assistant should always support the patient in correct posture prior to administration of block. After preparation and premedication as per standard protocol, patients will be given epidural under aseptic precaution by anaesthesiologist.

\section{Thoracic Epidural Technique Paramedian Approach}

All the patients were preloaded with $10 \mathrm{~mL} / \mathrm{kg}$ of Ringer lactate solution 20 minutes prior to epidural. The epidural was performed with the patients in sitting position. 2\% Lidocaine $2 \mathrm{~mL}$ was infiltrated in the subcutaneous tissue, muscle, ligaments and epidural performed with 18 gauge Tuohy needle in the T11-12 interspace.

In Paramedian approach, the needle insertion site was 1$1.5 \mathrm{~cm}$ lateral to the spinous process of the cephalad vertebra of the interspace. After local infiltration, the epidural needle was advanced perpendicular to the back (not medial or cephalad), towards the lamina and walked cephalad to the interlaminar groove. The needle should be minimally advanced, since it passes directly into the epidural and subarachnoid space without further redirection. At this point, a glass or low resistance syringe was attached and the needle advanced using loss of resistance technique. If the upper lamina is encountered during needle advancement, the needle should be redirected medially without withdrawing the needle. If the needle is withdrawn, the position is easily lost and difficult to relocate. After redirecting medially, the needle is advanced into the epidural space through ligamentum flavum. If bone is still contacted, it should be taken as an attempt and the needle should be walked along the interlaminar groove medially until advancement is possible. It should be noted that with the paramedian approach, there may be no resistance to injection until the Ligamentum Flavum is encountered.

\section{Median Approach}

The epidural was performed with the patients in sitting position and $2 \%$ Lidocaine $2 \mathrm{~mL}$ was infiltrated in the subcutaneous tissue, muscle and ligaments. And epidural performed with 18 gauge Tuohy needle in the T11-12 interspace. Patients were supported in the modified sitting position with active flexion (Bonica.J). ${ }^{7}$ The midline approach was used with the needle inclined $90^{\circ}-110^{\circ}$ cephalad to the skin. ${ }^{8}$ 18-gauge epidural catheter advanced to a depth of $5 \mathrm{~cm}$ in the epidural space. All are Portex catheters, made of nylon, with a bullet tip and three lateral openings. We compared the variables like number of attempts to find the epidural space, incidence of Dural tap, bloody tap, easy threading of catheter, incidence of pain during catheterisation, the time taken to identify the epidural space and resistance to catheter insertion in both the groups.

\begin{tabular}{|c|c|c|c|}
\hline Sl. No. & SURGERIES & Group M & Group P \\
\hline 1. & Gastrojejunostomy & 4 & 4 \\
\hline 2. & Open Cholecystectomy & 17 & 17 \\
\hline 3. & $\begin{array}{c}\text { Incisional Hernia } \\
\text { Mesh Repair }\end{array}$ & 14 & 13 \\
\hline 4. & Nephrectomy & 4 & 4 \\
\hline 5. & Laparotomy & 7 & 3 \\
\hline 6. & $\begin{array}{c}\text { Epigastric Hernia } \\
\text { Anatomical Repair }\end{array}$ & 2 & 2 \\
\hline 7. & Pyelolithotomy & 2 & 4 \\
\hline 8. & Hemicolectomy & 0 & 1 \\
\hline 9. & Cystogastrostomy & 0 & 1 \\
\hline 10. & $\begin{array}{c}\text { Loop Colostomy } \\
\text { Reconstruction }\end{array}$ & 0 & 1 \\
\hline \multicolumn{2}{|c|}{ Distribution of Surgeries in Group M and Group P } \\
\hline
\end{tabular}




\section{Statistical Analysis}

Collected data was analysed using Epi info software version 7. The results are obtained in the form of range, mean and standard deviation. The proportion comparison was done using chi-square test. Mean values were compared by using independent sample $t$ test. The probability value ' $p$ ' of less than 0.05 was considered statistically significant.

\section{RESULTS}

The study was completed in all the 100 patients posted for upper abdominal surgeries. Among them, 50 patients belonged to Group M (median approach) and 50 patients belonged to Group P (paramedian approach).

There was no statistically significant difference in the groups when the age was compared.

\begin{tabular}{|c|c|c|c|c|}
\hline \multirow{2}{*}{ Age group } & \multicolumn{2}{|c|}{ Median } & \multicolumn{2}{|c|}{ Paramedian } \\
\hline & No. & $\%$ & No. & $\%$ \\
\hline$<30$ & 3 & 6 & 7 & 14 \\
\hline $31-40$ & 14 & 28 & 14 & 28 \\
\hline $41-50$ & 18 & 36 & 12 & 24 \\
\hline $51-60$ & 15 & 30 & 17 & 34 \\
\hline Total & 50 & 100 & 50 & 100 \\
\hline Range & \multicolumn{2}{|c|}{$23-60$} & \multicolumn{2}{|c|}{$21-60$} \\
\hline Mean & \multicolumn{2}{|c|}{45.9} & \multicolumn{2}{|c|}{44.8} \\
\hline S.D. & \multicolumn{2}{|c|}{8.98} & \multicolumn{2}{|c|}{11.8} \\
\hline 'p' & \multicolumn{4}{|c|}{$\begin{array}{c}\mathrm{T}=0.543 ; \mathrm{p}=0.588 ; \text { not significant } \\
\text { Chi } \mathrm{sp}-2.93 ; \mathrm{p}=0.4\end{array}$} \\
\hline & & ibuti & & \\
\hline
\end{tabular}

\begin{tabular}{|c|c|c|c|c|}
\hline \multirow{2}{*}{ Sex } & \multicolumn{2}{|c|}{ Median } & \multicolumn{2}{c|}{ Paramedian } \\
\cline { 2 - 5 } & No. & $\mathbf{\%}$ & No. & \% \\
\hline Males & 22 & 44 & 22 & 44 \\
\hline Females & 28 & 56 & 28 & 56 \\
\hline Chi square value & \multicolumn{3}{|c|}{ 1; not significant } \\
\hline 'p' Sex Distribution \\
\hline
\end{tabular}

According to statistical analysis, the sex pattern was equally distributed in group $\mathrm{M}$ and group $\mathrm{P}$. This shows no significant difference between the groups.

\begin{tabular}{|c|c|c|}
\hline Weight (in kg) & Median & Paramedian \\
\hline Range & $40-65$ & $40-65$ \\
\hline Mean & 51.24 & 52.68 \\
\hline S.D. & 6.07 & 6.48 \\
\hline 'p' & \multicolumn{2}{|c|}{$\mathrm{T}=1.14 ; \mathrm{p}=0.25 ; \mathrm{NS}$} \\
\hline \multicolumn{3}{|c|}{ Weight Distribution } \\
\hline
\end{tabular}

In our study, the weight distribution shows no significant difference between the groups.

\begin{tabular}{|c|c|c|}
\hline HT & Median & Paramedian \\
\hline Range & $149-174$ & $150-170$ \\
\hline Mean & 158.98 & 159.5 \\
\hline S.D. & 6.44 & 6.08 \\
\hline 'p' & T $=0.43 ; \mathrm{p}=0.67, \mathrm{NS}$ \\
\hline \multicolumn{3}{|c|}{ Height Distribution } \\
\hline
\end{tabular}

There was no statistically significant difference between the group $\mathrm{M}$ and group $\mathrm{P}$.

\begin{tabular}{|c|c|c|c|c|}
\hline \multirow{2}{*}{ ASA } & \multicolumn{2}{|c|}{ Median } & \multicolumn{2}{c|}{ Paramedian } \\
\cline { 2 - 5 } & No. & $\%$ & No. & $\%$ \\
\hline I & 29 & 58 & 32 & 64 \\
\hline II & 21 & 42 & 18 & 36 \\
\hline Chi square value & \multicolumn{3}{|c|}{0.378} \\
\hline 'p' & \multicolumn{3}{|c|}{ 0.53; not significant } \\
\hline \multicolumn{4}{|c|}{ ASA Grading } \\
\hline
\end{tabular}

According to the American Society of Anesthesiologists grading of patients, the $\mathrm{p}$ value was 0.53 , it shows statistically no significant difference between the groups.

\section{Number of Attempts}

When the number of attempts to find the epidural space for both group $\mathrm{M}$ and group $\mathrm{P}$ were compared, in 42 patients out of 50 in group $P$, the space was identified in $1^{\text {st }}$ attempt (i.e. $84 \%$ ) and $16 \%$ of the patients were identified in $2^{\text {nd }}$ attempt.

In group $\mathrm{M}$, one attempt was needed in $60 \%$ of the patients (30), two attempts in 38\% (19 patients) and three attempts in $2 \%$ (1 patient). The statistical chi-square test analysis shows significant difference between both groups and the chi-square value was 7.481 and the $p$ value was 0.024 . This shows the risk of attempts was more in median approach when compared to paramedian approach.

\begin{tabular}{|c|c|c|c|c|c|c|}
\hline \multirow{2}{*}{ Group } & & \multicolumn{3}{|c|}{ No. of Attempts } & \multirow[b]{2}{*}{ Total } & \multirow{7}{*}{$\begin{array}{c}\text { Chi sq. test } \\
=7.481 \\
\mathrm{P} \text { value }= \\
0.024 \\
\text { significant }\end{array}$} \\
\hline & & 1 & 2 & 3 & & \\
\hline \multirow{2}{*}{ Median } & $\begin{array}{c}\text { No. of } \\
\text { patients }\end{array}$ & 30 & 19 & 1 & 50 & \\
\hline & $\%$ & $60 \%$ & $38 \%$ & $2 \%$ & $100 \%$ & \\
\hline \multirow{2}{*}{$\begin{array}{c}\text { Parame } \\
\text { dian }\end{array}$} & $\begin{array}{c}\text { No. of } \\
\text { patients }\end{array}$ & 42 & 8 & 0 & 50 & \\
\hline & $\%$ & $84 \%$ & $16 \%$ & $0 \%$ & $100 \%$ & \\
\hline Total & $\begin{array}{c}\text { No. of } \\
\text { patients }\end{array}$ & 72 & 27 & 1 & 100 & \\
\hline
\end{tabular}

In our study, the time to identify the epidural space from skin to the epidural space was minimal in paramedian epidural approach, and it ranged between 2-8 minutes in group $P$, the mean value was 3.94 , standard deviation was 1.58 . But in median epidural approach, the time range was 5-12 minutes, Mean was 8.56, standard deviation was 1.68 . The paramedian epidural approach took minimal time duration to locate the epidural space [p value 0.001 .

\begin{tabular}{|c|c|c|}
\hline Time & Median & Paramedian \\
\hline Range & $5-12$ & $2-8$ \\
\hline Mean & 8.56 & 3.94 \\
\hline S.D. & 1.68 & 1.58 \\
\hline 'p' T & T = 14.15; $\mathrm{p}=0.001$, significant \\
\hline \multicolumn{3}{|c|}{ Time to identify epidural space } \\
\hline
\end{tabular}




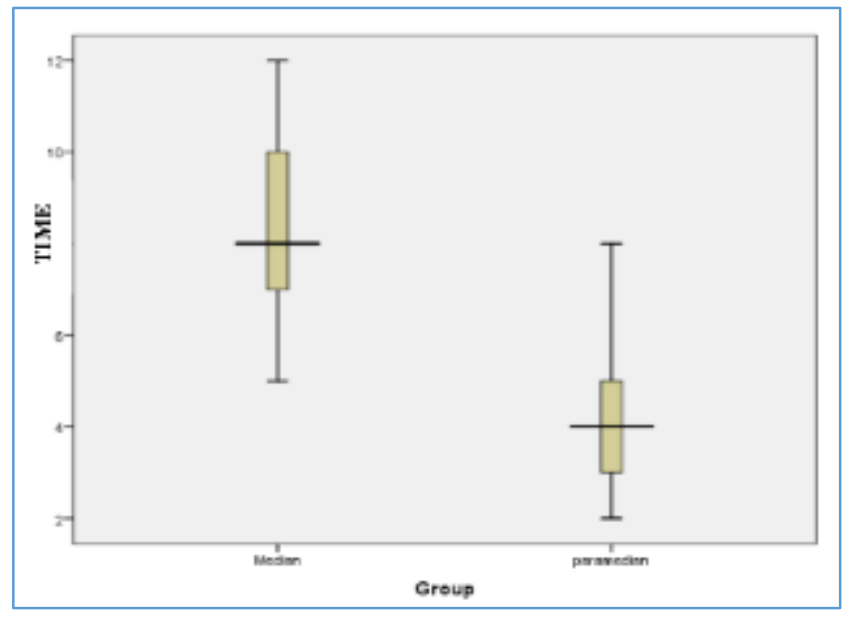

Figure 1. Time range to identify Epidural Space

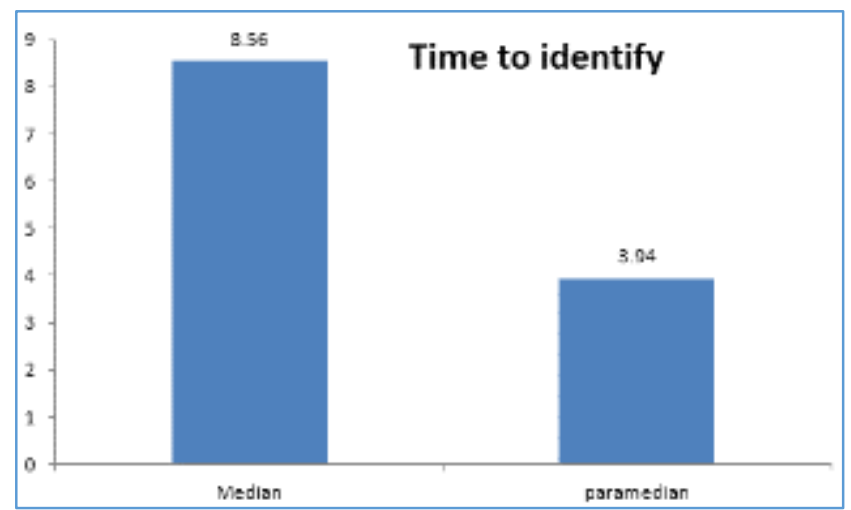

Figure 2. Mean time to identify Epidural Space

\section{Dural Tap}

The occurrences of dural tap was in 18\% of patients in group $\mathrm{M}$ and $2 \%$ in group $\mathrm{P}$ [p value 0.002]. Incidence of Dural puncture was higher in median epidural approach.

\begin{tabular}{|c|c|c|c|c|}
\hline \multirow{2}{*}{ Dural Tap } & \multicolumn{2}{|c|}{ Median } & \multicolumn{2}{c|}{ Paramedian } \\
\cline { 2 - 5 } & No. & $\%$ & No. & $\%$ \\
\hline Nil & 41 & 82 & 49 & 98 \\
\hline Yes & 9 & 18 & 1 & 2 \\
\hline Chi square value & \multicolumn{3}{|c|}{5.44} \\
\hline 'p' $0.02 ;$ significant \\
\hline \multicolumn{3}{|c|}{ Incidence of Dural Tap } \\
\hline
\end{tabular}

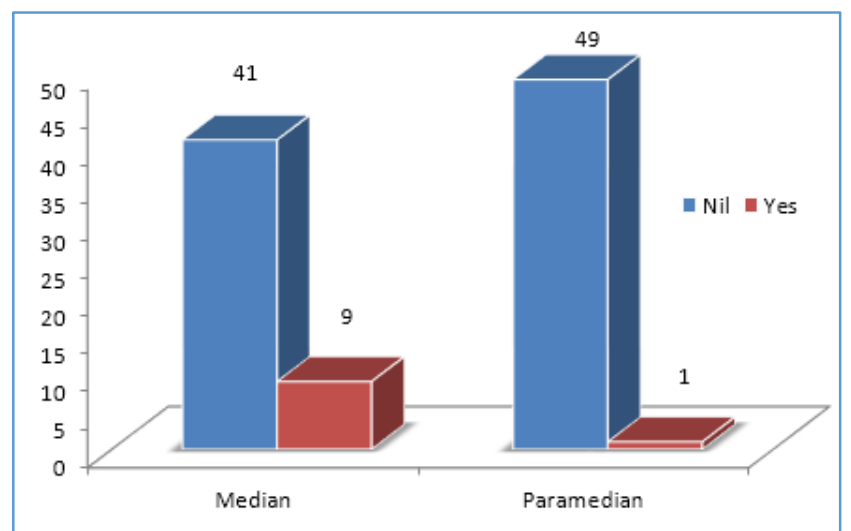

\section{Bloody Tap}

Figure 3. Incidence of dural Tap

Statistical analysis shows that the occurrence of bloody tap in paramedian epidural approach was $6 \%$ (3 patients) when compared to median epidural approach $16 \%$ ( 8 patients). The chi-square value was 4.396 and the $p$ value was 0.03 . The number of bloody tap was higher in median epidural approach.

\begin{tabular}{|c|c|c|c|c|}
\hline \multirow{2}{*}{ Bloody tap } & \multicolumn{2}{|c|}{ Median } & \multicolumn{2}{c|}{ Paramedian } \\
\cline { 2 - 5 } & No. & $\mathbf{\%}$ & No. & \% \\
\hline No & 42 & 82 & 47 & 94 \\
\hline Yes & 8 & 16 & 3 & 6 \\
\hline Chi square value & \multicolumn{4}{|c|}{4.396} \\
\hline 'p' value & \multicolumn{3}{|c|}{0.03 significant } \\
\hline \multicolumn{4}{|c}{ Incidence of Bloody tap } \\
\hline
\end{tabular}

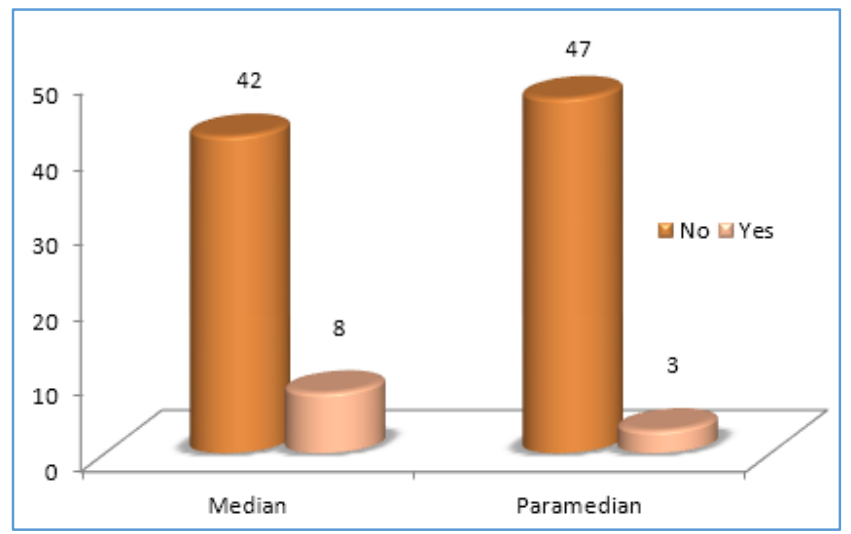

Figure 4. Incidence of Bloody Tap

\section{Easy Threading of the Catheter}

By using chi-square test the value was 7.527. This shows that difficult threading of the epidural catheter in median epidural approach was $14 \%$ when compared to paramedian epidural approach $(0 \%)$, p value 0.006 . In our study, threading of the epidural catheter was easy in paramedian epidural approach when compared to median epidural approach.

\begin{tabular}{|c|c|c|c|c|}
\hline \multirow{2}{*}{ Easy } & \multicolumn{2}{|c|}{ Median } & \multicolumn{2}{c|}{ Paramedian } \\
\cline { 2 - 5 } & No. & $\mathbf{\%}$ & No. & \% \\
\hline No (Difficult) & 7 & 14 & & \\
\hline Yes & 43 & 86 & 50 & 100 \\
\hline Chi square value & \multicolumn{4}{|c|}{7.527} \\
\hline 'p' 0.006 ; significant \\
\hline \multicolumn{3}{|c|}{ Easiness of Threading Catheter } \\
\hline
\end{tabular}

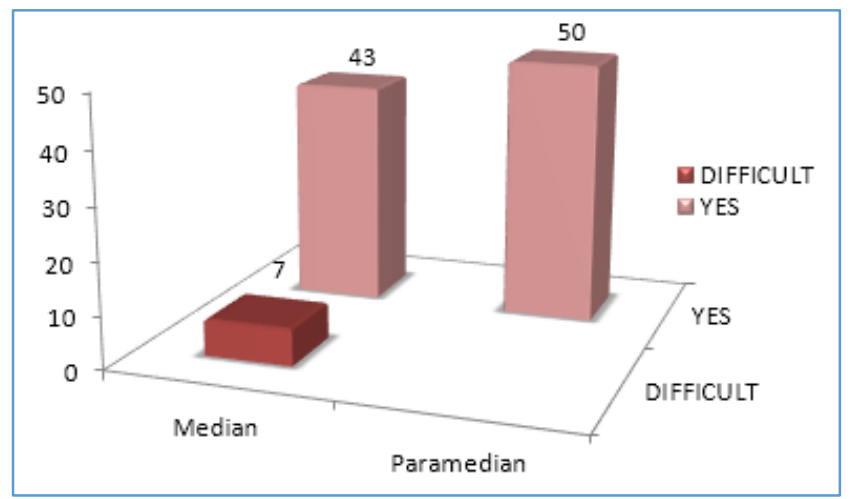

Figure 5. Easiness of Threading Catheter

\section{Pain during Catheter Threading}

Pain during catheter threading was analysed. In median epidural approach, mild pain was found in 35 patients $(70 \%)$ and moderate pain was found in 15 patients (30\%). In paramedian epidural catheter insertion, 8 patients $(16 \%)$ experienced mild pain [p 0.001]. 


\begin{tabular}{|c|c|c|c|c|}
\hline \multirow{2}{*}{ Pain } & \multicolumn{2}{|c|}{ Median } & Paramedian \\
\cline { 2 - 5 } & No. & \% & No. & \% \\
\hline+ & 35 & 70 & 8 & 16 \\
\hline++ & 15 & 30 & 0 & 0 \\
\hline Nil & 0 & 0 & 42 & 84 \\
\hline Chi square value & \multicolumn{3}{|c|}{73.95} \\
\hline 'p' & \multicolumn{3}{|c|}{001 ; significant } \\
\hline \multicolumn{3}{|c|}{ Pain during Catheter Threading } \\
\hline
\end{tabular}

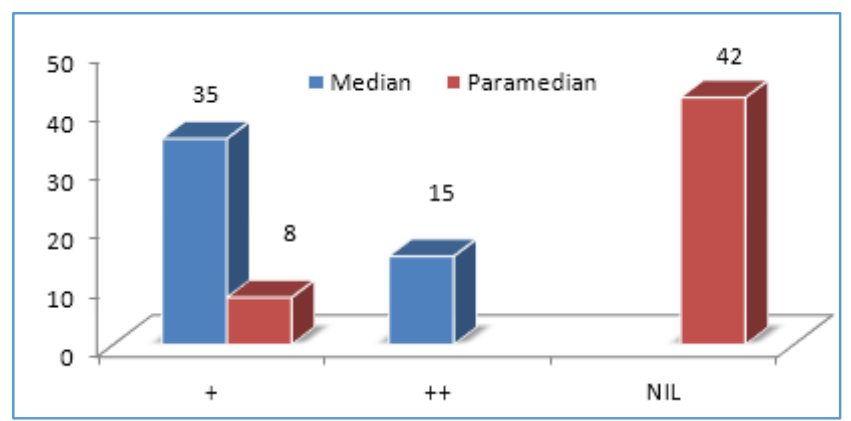

Figure 6. Occurence of pain during Catheter Threading

\section{Resistance to Catheter Insertion}

\begin{tabular}{|c|c|c|c|c|}
\hline \multirow{2}{*}{ Resistance } & \multicolumn{2}{|c|}{ Median } & \multicolumn{2}{c|}{ Paramedian } \\
\cline { 2 - 5 } & No. & $\mathbf{\%}$ & No. & \% \\
\hline Yes & 24 & 48 & 3 & 6 \\
\hline No & 26 & 52 & 47 & 94 \\
\hline Chi square value & \multicolumn{3}{|c|}{22.37} \\
\hline 'p' 0.001 ; significant \\
\hline \multicolumn{3}{|c|}{ Resistance to Catheter Insertion } \\
\hline
\end{tabular}

In group M, 24 patients (48\%) had resistance to catheter insertion. In group $P, 3$ patients had resistance $(6 \%)$ [p value 0.001]. This statistical analysis shows the resistance to catheter threading was minimal in group $\mathrm{P}$ when compared to group M.

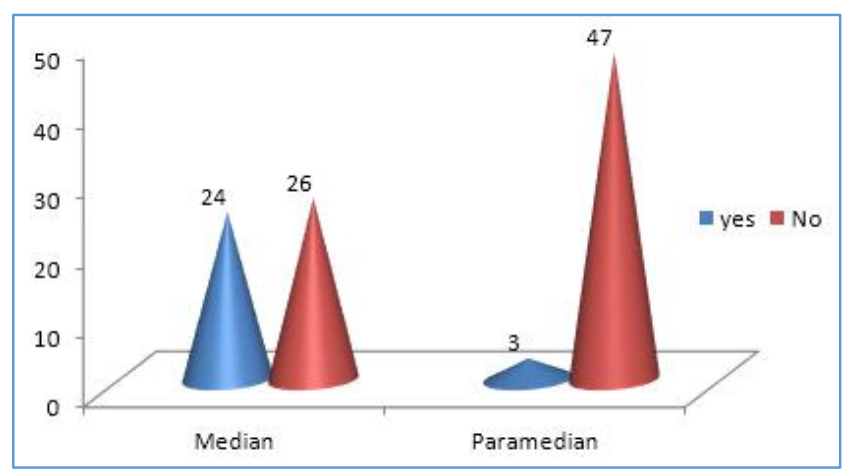

Figure 7. Resistance of Catheter Threading

\section{DISCUSSION}

\section{Number of Attempts to Find the Epidural Space}

Mericq, O; Simon, A; Fillette, D, et al concluded the paramedian epidural approach was easier and had fewer attempts to perform the epidural anaesthesia. ${ }^{9}$ Subrata Podder, MD et al, Neeraj Kumar, MD, L. N. Yaddanapudi, MD and Pramila Chari, MD- noted that seventeen patients in the midline group required more than two attempts for epidural insertion, with active flexion of the back required for needle insertion. ${ }^{10}$ Only one patient in the paramedian group required more than two attempts, $p<0.01$. There was more resistance to catheter advancement ( $p=0.023)$, blood in the catheter $(p=0.022)$, and paraesthesia $(\mathrm{p}=0.010)$. In addition, the midline approach was associated with more discomfort than the paramedian approach.

In our study, when compared to the number of attempts to find the epidural space for both group $\mathrm{M}$ and group $\mathrm{P}$, in 42 patients out of 50 in group $\mathrm{P}$, the space was identified in $1^{\mathrm{st}}$ attempt (i.e. $84 \%$ ) and $16 \%$ of the patients were identified in $2^{\text {nd }}$ attempt. In group $M, 60 \%$ of the patients (30) had 1 attempt, $2^{\text {nd }}$ attempt was in 38\% (19 patients) and 3rd attempt was in $2 \%$ ( 1 patient). [p value 0.024 ].

This shows the risk of increased attempts in median approach when compared to paramedian approach.

\section{Bloody Tap}

Mericq, 0; Simon, A; Fillette, D, et al found that the incidence of bloody tap was $3.2 \%$ in median approach compared to $2.8 \%$ in paramedian approach. ${ }^{9}$ Subrata Podder, MD et al, Neeraj Kumar, MD, L. N. Yaddanapudi, MD and Pramila Chari, MD, et al- noted that there were more catheter-related problems in the midline group, blood in the catheter $(p=0.022)$. Jaucot et al (1986) noted lower incidence of paraesthesia (22\% vs. $42.5 \%$ ) and vascular puncture using paramedian approach. ${ }^{10}$

In our study, statistical analysis shows that the occurrence of bloody tap in paramedian epidural approach was $6 \%$ (3 patients) while it was $16 \%$ in median epidural approach [p 0.03]. The number of bloody tap was higher in median epidural approach.

\section{Dural Tap}

Sprung et al11 (1999) found no differences in success rate between paramedian and midline approach. In Epiduroscopic Cadaver Study (1988), using midline approach, there was dural tenting, the catheter was unpredictable due to strands of connective tissue restricting movement of dura mater. ${ }^{12}$ In Paramedian approach, advance in a cephalad direction without dural tenting, 3-dimensional insight shows the risk was minimal in this approach.

Mericq, O; Simon, A; Fillette, D, et al observed the safety of the paramedian approach for epidural anaesthesia versus the midline approach and found that the incidence of dural tap was $0.9 \%$ in median approach, $0.3 \%$ in paramedian approach. ${ }^{9}$ In my study, the occurrence of dural tap was $18 \%$ in group $\mathrm{M}$ and $2 \%$ in group P. [p=0.002]. This data shows the statistically significant difference. Incidence of dural puncture was higher in median epidural approach.

\section{Easy Threading of the Catheter}

Kazuhide Takeyama, Hajime Yamazaki, Miho Maeda, Kyoko Tomino and Toshiyasu Suzuki et al noted straight advancement of epidural catheter-comparative assessments by method, and site of epidural needle puncture and angle of puncture shows the significant difference with paramedian epidural technique ${ }^{13}$ and observed easy threading possible according to the angulations.

Blomberg $\mathrm{R}$ et $\mathrm{al}^{4}$ (1989) reported $4 \%$ paraesthesia using paramedian and $36 \%$ using midline. Blomberg found resistance to catheter insertion less common with paramedian approach, steeper angle of entry of the paramedian epidural needle into the epidural space, facilitating catheter insertion. They observed easy threading with paramedian approach.

Nishimoto N, Hibi K, Ueno O, et al [1978] found that the threading and insertion was easy with paramedian compared to median approach.14 
This study shows that difficult threading of the epidural catheter in median epidural approach was $14 \%$ when compared to paramedian epidural approach $0 \%$ [p 0.006]. Easy threading of the epidural catheter was successful in paramedian epidural approach when compared to median epidural approach.

\section{Pain during Catheterisation}

Mericq, O; Simon, A; Fillette, D, et al noted the safety of the paramedian approach for epidural anaesthesia versus the midline approach and observed that the incidence of paraesthesia was $8.5 \%$ in median approach, $7.5 \%$ in paramedian approach, with no statistically significant difference between the groups, ${ }^{9}$

In Subrata Podder, MD, Neeraj Kumar, MD, L. N. Yaddanapudi, MD and Pramila Chari, MD, et al study; there were more catheter-related problems in the midline group, paraesthesia $(\mathrm{P}=0.010) .{ }^{9}$ Giebler $\mathrm{RM}$ et al ${ }^{15}$ observed the incidence of pain during catheterisation was higher in midline epidural approach. Jaucotet al (1986) noted lower incidence of paraesthesia (22\% vs. $42.5 \%$ ) and vascular puncture using paramedian approach. ${ }^{16}$ Blomberg R et al (1989) reported $4 \%$ paraesthesia using paramedian and $36 \%$ using midline. 4

In our study, Pain during catheter threading was assessed. In median epidural approach, mild pain was found in 35 patients $(70 \%)$ and moderate pain was found in 15 patients (30\%). In paramedian epidural catheter insertion, 8 patients (16\%) experienced mild pain [p value 0.001 ].

\section{Resistance to Catheter Insertion}

Subrata Podder, MD, Neeraj Kumar, MD, L. N. Yaddanapudi, MD and Pramila Chari, MD, et al study shows resistance to catheter advancement $(\mathrm{p}=0.023)$.

Jaucot et al (1986) study noted difference in catheter stiffness may play a significant role, Catheter insertion was significantly faster and easier using paramedian epidural technique. ${ }^{10}$ Blomberg R et al ${ }^{4}$ (1989) found resistance to catheter insertion less common with paramedian approach. Nishimoto $\mathrm{N}^{14}$, Hibi $\mathrm{K}$, Ueno $\mathrm{O}$, et al noted that insertion of a catheter by paramedian lumbar epidural puncture was found to be with less resistance compared to the median epidural technique.

In our study, both group $M$ and $P$ showed certain resistance to catheter insertion. In group M, 24 patients (48\%) had resistance to catheter insertion. In group $P$, only 3 patients had resistance $(6 \%)$ [p value 0.001 ]. That was significant in paramedian approach.

\section{Time to Identify the Epidural Space}

M. Leeda, R. Stienstra, M. S. Arbous, A. Dahan et al study observed the easy and faster time to find the epidural space was by the paramedian approach. ${ }^{17}$ In our study, the time to identify the epidural space from skin to the epidural space was minimal in paramedian epidural approach; this range was 2-8 minutes [3.94 \pm 1.58$]$. But in median epidural approach, the range was $5-12$ minutes [8.56 \pm 1.68$]$. This shows that more time was taken to find the epidural space through median epidural approach [p value 0.001$]$.

\section{CONCLUSION}

The location of epidural space in a patient posted for upper abdominal surgeries was found to be easier and has lesser complications by paramedian approach when compared to median epidural approach.

\section{REFERENCES}

[1] Dogliotti AM. Segmental peridural spinal anesthesia: a new method of block anesthesia. The American Journal of Surgery 1933;20(1):107-118.

[2] Brown DL. Spinal, epidural and caudal anesthesia. In: Miller RD. edr. Miller's Anesthesia. $7^{\text {th }}$ edn. Elsevier 2005:1653-83.

[3] Morgan GE, Mikhail MSM, Murray MJM. Clinical anesthesiology. $3^{\text {rd }}$ edn. McGraw-Hill 2002.

[4] Blomberg RG, Jaanivald A, Walther S. Advantages of the paramedian approach for lumbar epidural analgesia with catheter technique: a clinical comparison between midline and paramedian approaches. Anaesthesia 1989;44(9):742-6.

[5] Carrie LES. The paramedian approach to the epidural space. Technique and choice of needle. Anaesthesia 1977;32(7):671-3.

[6] Griffin RM, Scott RP. Forum. A comparison between the midline and paramedian approach to the extradural space. Anaesthesia 1984;39(6):584-6.

[7] Bonica JJ, Backup PH, Anderson CE, et al. Peridural block: analysis of 3,637 cases and a review. Anesthesiology 1957;18(5):723-84.

[8] Minville V, Fourcade O, Grousset D, et al. Spinal anesthesia using single injection small-dose bupivacaine versus continuous catheter injection techniques for surgical repair of hip fracture in elderly patients. Anesth Analg 2006;102(5):1559-63.

[9] Mericq O, Simon A, Fillette D, et al. Safety of the paramedian approach for epidural anaesthesia versus the midline approach. European Journal of Anaesthesiology 2000;17:96.

[10] Podder S, Kumar N, Yaddanapudi LN, et al. Paramedian lumbar epidural catheter insertion with patients in the sitting position is equally successful in the flexed and unflexed spine. Anesth Analg 2004;99(6):1829-32.

[11] Sprung J, Bourke DL, Grass J, et al. Predicting the difficult neuraxial block: a prospective study. Anaesth Analg 1999;89(2):384-9.

[12] Blomberg R. The dorsomedian connective tissue band in the lumbar epidural space of humans: an anatomical study using epiduroscopy in autopsy cases. Anesth Analg 1986;65(7):747-52.

[13] Takeyama K, Yamazaki HJ, Maeda M, et al. Straight advancement of epidural catheter. Tokai J Exp Clin Med 2004;29(2):27-33.

[14] Masui N. A method for insertion of a catheter by paramedian lumbar epidural puncture. (Author's Transl) 1978;27(6):628-33, 6.

[15] Giebler RM, Scherer RU, Peters J. Incidence of neurological complications related to thoracic epidural catheterization. Anaestheiology 1997;86(1)55-63.

[16] Jaucot J. Paramedian approach of the peridural space in obstetrics. Acta Anaesthesiol Belg 1986;37(3):187-92.

[17] Leeda M, Stienstra R, Arbous MS, et al. Lumbar epidural catheter insertion: the midline vs. the paramedian approach. European Journal Anaesthesiology 2005;22(11):839-42. 